\title{
Dietary behaviours and sociocultural demographics in Northern Ireland
}

\author{
BY M. E. BARKER*, S. I. MCCLEAN, K. A. THOMPSON AND N. G. REID† \\ Centre for Applied Health Studies, University of Ulster, Coleraine, Northern Ireland BT52 ISA
}

(Received 27 September 1989 - Accepted 11 April 1990)

\begin{abstract}
Subjects aged 16-64 years $(592 ; 258$ men and 334 women), randomly selected from the population of Northern Ireland, kept a $7 \mathrm{~d}$ weighed record of all food and drink consumed. Social, personal and anthropometric data were also collected. From the weighed records food consumption was described in terms of forty-one food groups. Using principal components analysis, four distinct dietary patterns were generated which were identified as a traditional diet, a cosmopolitan diet, a convenience diet and a 'meat and two veg' diet. These dietary patterns were then correlated with sociocultural, lifestyle and anthropometric variables. It is clear that dietary behaviour is influenced by a number of inter-related sociocultural demographics and that identifiable population groups in Northern Ireland have different dietary behaviours.
\end{abstract}

Weighed intake: Dietary patterns: Sociocultural demographics: Northern Ireland

Individual food patterns may be influenced by a host of social, psychological, sensory and economic factors. Theoretical models for understanding and classifying food consumption patterns have been proposed by a number of researchers (for example, Passim \& Bennet, 1943; Jellife, 1967; Ellis et al. 1976). Such models relate dietary behaviour to environmental and economic factors. Empirical population studies of dietary behaviours have conventionally interpreted dietary behaviour in terms of nutrient intake (Bingham et al. 1981; Fehily et al. 1984a, $b$; Barker et al. 1989). Although such studies have shown sociodemographic differences in nutrient intake (Fehily et al. 1984 b; Barker et al. 1989) they ignore the fact that foods (and nutrients) are consumed in combinations, and have not identified dietary practices associated with individuals or groups of individuals. In addition, information on intakes of individual nutrients ignore the potential confounding effect of nutrient interrelationships.

In the UK recently there has been increasing interest in quantifying food sources of nutrients (Thomson et al. 1985; Hackett et al. 1986; Cade \& Margetts, 1988) and, in an indepth sociological study of women, food and families, Charles \& Kerr (1988) explored the way in which food and food practices reflect the social divisions of class, age and sex. However, no UK study of dietary behaviours has focussed on understanding individual eating patterns.

In the US seven distinct eating patterns have been identified by Schwerin et al (1981, 1982) using the Ten-State Survey, National Health and Nutrition Examination Survey (NHANES 1) and National Food Consumption Survey (NFCS) dietary data in an exploratory factor analysis. Similarly, Gex-Fabry et al. (1988) analysed dietary information from 939 Swiss adults to identify three distinct eating patterns using principal components analysis. Studies (Hara et al. 1985; Hirayama 1985) in Japan have also examined patterns of food consumption in relation to disease risk using exploratory factor analysis.

Present addresses: *Dairy Council for Northern Ireland, 456 Antrim Road, Belfast, Northern Ireland BT15 5GB. † Department of Health Sciences, Coventry Polytechnic, Coventry CV1 5FB. 
The present investigation was undertaken to explore the dietary behaviour of adults in Northern Ireland who participated in the Northern Ireland Diet and Health Study (Barker et al. 1989). In order to gain insight into the extent to which sociocultural and anthropometric factors may govern dietary behaviour, individual eating patterns have been examined in relation to the variables of sex, age, marital status, religion, geographical location, household size, smoking and drinking habits and relative weight index.

\section{METHODS}

\section{Subjects}

A detailed account of the sampling methods, design of instruments for data collection and methods of data collection has been provided elsewhere (Barker et al. 1989). The study was based on a two-stage sample; first of Northern Ireland households and second of individuals from the sampled households. The method of Kish (1965) was used to extract a sample of 797 eligible subjects aged between 16 and 64 years who reflected the sex and age distribution of the population. Of these, 616 subjects completed the full range of study measures and 592 subjects ( $74 \%$ of the eligible sample) satisfactorily completed the weighed record of food intake. Table 1 provides the sex, age and socio-economic group distributions for the cooperating sample. The socio-economic profile of the sample was ascertained by reference to the current occupation of the head of the household or past occupation if the head of the household was retired, using the Registrar General's classification (Office of Population, Censuses and Surveys, 1980). Using this classification social class was subdivided into four categories: those in social classes I, II and III nonmanual were categorized as 'non-manual', those in social classes III manual, IV and V were categorized as 'manual', with the unemployed and other unclassified subjects making up the remaining two categories.

\section{Dietary information}

Dietary information was collected through direct weighing of intake over $7 \mathrm{~d}$. This method is accepted as one of the most precise available (Marr, 1971; Fehily, 1983). A full account of the use of this method is provided by Barker et al. (1989). From these values, weights of a range of food groups consumed by each subject were calculated. Table 2 shows the food groups used with means, standard deviations and coefficients of variation for daily consumption $(\mathrm{g})$. Since clearly some of these variables have skewed distributions the standard deviations are not in all cases an appropriate measure of dispersion. However, standard deviations and coefficients of variation have been included for the purposes of comparison.

\section{Sociocultural and anthropometric information}

Personal and social information such as marital status, socio-economic status, religion, domicile and household number were ascertained by interviewer-administered questionnaire. Information on smoking and drinking habits was similarly collected.

Subjects were classified into three categories of smoking habit: current smokers, exsmokers and subjects who had never smoked. Drinking habit was classified into four categories, based on the frequency of consumption of alcohol; subjects who drank more often than once weekly, subjects who drank once weekly, subjects who drank less than once weekly and subjects who never drank alcohol.

Height and weight were obtained as part of the study protocol (Barker et al. 1989). Height was measured using a folding stadiometer and weight measured in light clothing using a Soehnle digital electronic scale. Both instruments were obtained from CMS 
Table 1. Demographic characteristics of sample

\begin{tabular}{lrrr}
\hline & Men & Women & All \\
\hline Age-range (years) & & & \\
$16-29$ & 105 & 110 & 215 \\
$30-39$ & 64 & 90 & 154 \\
$40-49$ & 51 & 70 & 121 \\
$50-64$ & 38 & 64 & 102 \\
Socio-economic group & & & \\
$\quad$ Non-manual & 101 & 132 & 233 \\
$\quad$ Manual & 103 & 113 & 216 \\
$\quad$ Unemployed & 39 & 37 & 76 \\
Other (unclassified) & 15 & 52 & 67 \\
$\quad$ Total & 258 & 334 & 592 \\
\hline
\end{tabular}

* The other category contained subjects who could not be classified using the head of household's occupation. In many cases the head of household was economically inactive.

Weighing Ltd, London. Body mass index (BMI) was calculated using the Quetelet index; weight $(\mathrm{kg}) /(\text { height } ; \mathrm{m})^{2}$.

\section{Statistical analysis}

Principal components analysis was carried out on the correlation matrix for the forty-one food groups described in Table 2 and the 592 co-operating subjects in the study. Principal components analysis is a statistical technique which produces linear combinations of the variables which account for as much of the variance as possible, and thus describe major patterns in the data. The first component is the linear combination which explains as much of the variance as possible, the second component is the linear combination of the variables which is independent of the first component and explains as much as possible of the remaining variance, and so on. The coefficients in these linear combinations are called the factor loadings, and by looking at the loadings of the variables represented in a component we build up a picture of the pattern which the component is describing. The chief advantage of the technique is that it summarizes a large number of variables into a small number of underlying patterns. The SPSSX (1983) statistical package (routine FACTOR) was used to identify the primary components which accounted for the main variation in dietary intake. For ease of interpretation the signs were reversed on the factor loadings for component four throughout. Factor scores were calculated for each individual and analysis of covariance was then used to explore the characteristics of subjects for each of the four main components identified. The SPSSX statistical package, routine ANOVA, was used to carry out this second stage of the analysis.

\section{RESULTS}

The first four components accounted for $6 \cdot 7,6 \cdot 0,4 \cdot 7$ and $4 \cdot 1 \%$ respectively of the total variation. In total, then, these factors represented cumulative percentage of 21.5 of the inter-individual variability. This is a similar pattern to that reported by Gex-Fabry et al. (1988). The relatively small percentage of the variance accounted for, is a result of basing our analysis on forty-one different food groups thus representing food intake at a microlevel. Had the food groups been aggregated, as in Scherwin et al. $(1981,1982)$, it is likely that we would have accounted for a larger proportion of the variance. However this approach would have rendered our interpretation of the dietary patterns less meaningful. 
Table 2. Food groups, used for classifying daily consumption $(\mathrm{g})$ by study group of 592 subjects from Northern Ireland

(Mean values, standard deviations and coefficients of variation)

\begin{tabular}{|c|c|c|c|}
\hline Food group & Mean & SI) & $\mathrm{CV}$ \\
\hline Bread & 129 & $74 \cdot 8$ & 0.6 \\
\hline Spreading fats & 20 & $13 \cdot 4$ & $0 \cdot 7$ \\
\hline Tea and coffee & 500 & $29 \cdot 7$ & $0 \cdot 1$ \\
\hline Cakes and desserts & 77 & $61 \cdot 0$ & 0.8 \\
\hline Potatoes & 124 & $81 \cdot 0$ & $0 \cdot 7$ \\
\hline Milk & 229 & $141 \cdot 6$ & $0 \cdot 6$ \\
\hline Preserves & 5 & $8 \cdot 8$ & $1 \cdot 8$ \\
\hline Eggs & 22 & $21 \cdot 9$ & $1 \cdot 0$ \\
\hline Chips & 58 & $57 \cdot 7$ & $1 \cdot 0$ \\
\hline Sausages & 11 & $15 \cdot 4$ & $1 \cdot 4$ \\
\hline Fruit & 51 & $61 \cdot 4$ & $1 \cdot 2$ \\
\hline Peas and beans & 30 & 27.9 & 0.9 \\
\hline Savoury pies & 20 & $24 \cdot 1$ & $1 \cdot 2$ \\
\hline Egg and cheese dishes & 6 & $16 \cdot 1$ & $2 \cdot 7$ \\
\hline Cream & 2 & $5 \cdot 1$ & $2 \cdot 5$ \\
\hline Beers & 193 & $497 \cdot 8$ & $2 \cdot 6$ \\
\hline Sauces & 11 & 13.9 & $1 \cdot 3$ \\
\hline Cheese & 10 & $14 \cdot 7$ & $1 \cdot 5$ \\
\hline White fish & 12 & 19.9 & $1 \cdot 7$ \\
\hline Nuts & 1 & 5.9 & $5 \cdot 9$ \\
\hline Meat & 40 & $33 \cdot 5$ & 0.8 \\
\hline Cider & 6 & 67.9 & $11 \cdot 3$ \\
\hline Vegetables & 66 & $48 \cdot 3$ & $0 \cdot 7$ \\
\hline Poultry & 17 & $20 \cdot 9$ & $1 \cdot 2$ \\
\hline Patés & 1 & $3 \cdot 3$ & $3 \cdot 3$ \\
\hline Wines, liqueurs, spirits & 17 & $38 \cdot 9$ & $2 \cdot 3$ \\
\hline Soft drinks & 89 & $122 \cdot 8$ & $1 \cdot 4$ \\
\hline Cooked meat dishes & 28 & $42 \cdot 6$ & $1 \cdot 5$ \\
\hline Rice and pasta & 17 & $31 \cdot 3$ & $1 \cdot 8$ \\
\hline Confectionery & 7 & $15 \cdot 3$ & $2 \cdot 2$ \\
\hline Canned meats & 4 & $10 \cdot 6$ & 2.6 \\
\hline Yoghurt & 8 & $28 \cdot 8$ & $3 \cdot 6$ \\
\hline Sugar & 15 & $22 \cdot 5$ & 1.5 \\
\hline Liver & 2 & 6.0 & $3 \cdot 0$ \\
\hline Fatty fish & 5 & $9 \cdot 9$ & $2 \cdot 0$ \\
\hline Soups & 20 & $35 \cdot 1$ & $1 \cdot 8$ \\
\hline Breakfast cereals & 18 & $31 \cdot 5$ & $1 \cdot 7$ \\
\hline Shellfish & 1 & $4 \cdot 4$ & $4 \cdot 4$ \\
\hline Bacon & 15 & $15 \cdot 4$ & $1 \cdot 0$ \\
\hline Fish products & 2 & 6.8 & $3 \cdot 4$ \\
\hline Miscellaneous & 159 & $218 \cdot 1$ & $1 \cdot 4$ \\
\hline
\end{tabular}

The first component could be described as a traditional Ulster diet reflecting a pattern of eating centred on core foods such as bread, spreading fats, cakes and desserts, tea and coffee and potatoes. These foods traditionally comprise the basic elements of breakfast, dinner, tea (afternoon and high) and supper menus. For this component high positive loadings were obtained for bread, spreading fats, tea and coffee, cakes and desserts, potatoes, milk, preserves, eggs, bacon and vegetables. High negative loadings were obtained for miscellaneous (mostly water), chips, wines, liqueurs and spirits, and rice and pasta.

The second component represented a diverse and cosmopolitan diet. It included a 
Table 3. Factor loadings (>0.15) of various food groups calculated from daily consumption by study group of 592 subjects from Northern Ireland for each component

\begin{tabular}{|c|c|c|c|c|}
\hline $\begin{array}{l}\text { Component } \ldots \\
\text { Food group }\end{array}$ & 1 & 2 & 3 & 4 \\
\hline Bread & +0.736 & -0.255 & - & $-0 \cdot 196$ \\
\hline Spreading fats & +0.725 & $-0 \cdot 180$ & - & $-0 \cdot 171$ \\
\hline Tea and coffee & +0.502 & $+0 \cdot 246$ & - & -0.170 \\
\hline Cakes and desserts & +0.439 & +0.219 & - & - \\
\hline Potatoes & +0.396 & -0.231 & +0.250 & +0.290 \\
\hline Milk & +0.395 & +0.195 & +0.228 & - \\
\hline Preserves & +0.343 & +0.238 & - & - \\
\hline Eggs & +0.343 & -0.208 & - & - \\
\hline Chips & $-0.24 I$ & -0.519 & +0.389 & - \\
\hline Sausages & - & -0.508 & +0.205 & - \\
\hline Fruit & $+0 \cdot 152$ & +0.475 & - & - \\
\hline Peas and beans & - & -0.425 & +0.282 & - \\
\hline Savoury pies & -0.193 & $-0 \cdot 380$ & +0.328 & - \\
\hline Fgg and cheese dishes & - & +0.323 & +0.222 & - \\
\hline Cream & - & +0.287 & +0.229 & - \\
\hline Beers & & -0.293 & +0.415 & - \\
\hline Sauces & - & - & +0.384 & +0.318 \\
\hline Cheese & +0.240 & +0.283 & +0.344 & -0.269 \\
\hline White fish & - & -0.172 & +0.222 & +0.182 \\
\hline Nuts & - & +0.183 & +0.364 & -0.507 \\
\hline Meat & +0.158 & -0.202 & $+0 \cdot 185$ & +0.397 \\
\hline Cider & - & - & +0.174 & $-0 \cdot 390$ \\
\hline Vegetables & +0.280 & +0.362 & +0.204 & +0.380 \\
\hline Poultry & - & - & - & +0.336 \\
\hline Patés & - & +0.243 & - & -0.295 \\
\hline Wines, liqueurs, spirits & -0.233 & +0.219 & +0.226 & +0.276 \\
\hline Soft drinks & -0.204 & -0.200 & +0.368 & - \\
\hline Cooked meat dishes & -0.210 & +0.203 & +0.291 & - \\
\hline Rice and pasta & -0.204 & +0.333 & +0.344 & +0.223 \\
\hline Confectionery & -0.196 & - & +0.191 & -0.223 \\
\hline Canned meats & +0.159 & -0.231 & $+0 \cdot 154$ & -0.171 \\
\hline Yoghurt & - & $+0 \cdot 155$ & +0.264 & -0.173 \\
\hline Sugar & $+0 \cdot 200$ & $+0 \cdot 190$ & - & $\ldots$ \\
\hline Liver & - & - & - & - \\
\hline Fatty fish & - & +0.219 & - & +0.192 \\
\hline Soups & - & - & - & - \\
\hline Breakfast cereals & +0.214 & +0.224 & - & - \\
\hline Shellfish & - & $+0 \cdot 200$ & +0.199 & +0.157 \\
\hline Bacon & +0.318 & -0.175 & - & - \\
\hline Fish products & - & - & - & - \\
\hline Miscellaneous & $-0 \cdot 246$ & $+0 \cdot 199$ & +0.334 & -0.239 \\
\hline
\end{tabular}

number of foods associated with modern concepts of healthy eating behaviour as well as foods that may be perceived to be prestigious. At the same time foods that could be considered to be either prosaic or relatively unhealthy were avoided. From Table 3 it is evident that for this component there were high positive loadings for fruit, vegetables, rice and pasta, egg and cheese dishes, cream, cheese, tea and coffee and patés. High negative loadings were obtained for chips, sausages, peas and beans, savoury pies and beer.

The third component represented a diet based on fast and convenience food. From Table 3 it is evident that high positive loadings were found for beer, chips, sauces, soft drinks, nuts, cheese, rice and pasta, savoury pies and cooked meat dishes.

The fourth component represents a meat and two veg diet. Such a combination of foods 
may be considered to be an archetypal British diet. From Table 3 it is clear that high positive loadings were found for meat, vegetables, poultry, sauces and potatoes, while negative loadings were found for nuts, cider, patés, cheese and confectionery.

\section{Demographic characteristics associated with the four main components}

The first three components showed a highly significant $(P<0.001)$ difference between male and female subjects. The first component (traditional diet) was more favoured by men, as was the third component (convenience diet), whilst the second component (cosmopolitan diet) was supported by women. No significant sex difference was apparent for the fourth component, although men tended more to this eating pattern. Due to the strong sex bias in eating patterns, analysis of covariance was performed separately on male and female subjects.

Factor scores associated with each individual were used to carry out analysis of covariance with age and BMI as covariates, and socio-economic group, marital status, religion, geographical location, smoking and alcohol consumption as main effects. Table 4 provides regression coefficients and significance levels for these analyses.

\section{Component one}

It is apparent from Table 4 that component one (traditional diet) was associated with a number of sociodemographic and lifestyle variables. Age had a significant $(P<0.001)$ effect with older subjects gravitating towards this eating pattern. Religion also had a significant $(P<0 \cdot 01)$ effect in the male sample; Roman Catholic men were more likely to adhere to this component. There were also significant $(P<0.01)$ differences between regular drinkers and non-drinkers; men and women who drank less often than once weekly and non-drinkers had the most positive association with this dietary pattern. Geographical location was also a significant $(P<0.05)$ factor in the analysis of the male cohort, with adherents to component one tending to live in rural areas. There were no significant associations between socio-economic group, marital status, smoking habit, BMI, household size and component one.

\section{Component two}

The second dietary pattern, component two (cosmopolitan diet) was not significantly associated with the covariate of BMI. Age was significantly $(P<0.001$ and $P<0.01$ for men and women respectively) associated with component two; older subjects favoured component two. Socio-economic group was highly significant $(P<0.001)$ in the analysis. Strong positive associations were observed between component two and subjects from nonmanual households. Marital status had also a significant $(P<0 \cdot 05)$ effect with married subjects tending towards this dietary regimen. Smoking habit had a significant $(P<0 \cdot 01)$ effect on component two in the female cohort with the association being positive for nonsmokers. There was also a significant $(P<0.05)$ association between drinking habit and component two in the female sample, women who drank at least once weekly tended to favour this eating pattern. Although household size was non-significant in the analysis, men and women living alone tended towards this dietary behaviour.

\section{Component three}

From Table 4 it is clear that component three (convenience diet) was significantly $(P<0.001)$ correlated with age for both men and women and younger subjects tended towards this eating pattern. There was also a significant $(P<0.05)$ relationship between BMI and component three in the female cohort. Women of low relative BMI tended to this component. Socio-economic group had a significant $(P<0.05)$ effect in the male sample; 
Table 4. Analysis of covariance of dietary behaviours of a study group of 592 subjects from Northern Ireland

\begin{tabular}{|c|c|c|c|c|c|c|c|c|}
\hline \multirow[t]{2}{*}{$\begin{array}{l}\text { Component } \ldots \\
\text { Dietary pattern } \dagger \ldots\end{array}$} & \multicolumn{2}{|c|}{$\begin{array}{c}1 \\
\text { Traditional }\end{array}$} & \multicolumn{2}{|c|}{$\stackrel{2}{\text { Cosmopolitan }}$} & \multicolumn{2}{|c|}{$\begin{array}{c}3 \\
\text { Convenience }\end{array}$} & \multicolumn{2}{|c|}{$\begin{array}{c}4 \\
\text { 'Meat and } \\
\text { two veg' }\end{array}$} \\
\hline & Men & Women & Men & Women & Men & Women & Men & Women \\
\hline \multicolumn{9}{|c|}{ Covariates (regression coefficients) } \\
\hline & $* * *$ & $* * *$ & $* * *$ & $* *$ & $* * *$ & $* * *$ & NS & NS \\
\hline Age & $\begin{array}{l}0.400 \\
\text { NS }\end{array}$ & $\begin{array}{l}0 \cdot 224 \\
\text { NS }\end{array}$ & $\begin{array}{l}0.267 \\
\text { NS }\end{array}$ & $\begin{array}{l}0 \cdot 115 \\
\text { NS }\end{array}$ & $\begin{array}{l}-0.333 \\
\text { NS }\end{array}$ & $\begin{array}{c}-0 \cdot 170 \\
*\end{array}$ & $\begin{array}{l}0.078 \\
\text { NS }\end{array}$ & $\begin{array}{l}0.014 \\
\text { NS }\end{array}$ \\
\hline $\begin{array}{l}\text { BMI } \\
\text { Factors (deviations from }\end{array}$ & $\begin{array}{r}0.023 \\
\text { Tand mea }\end{array}$ & ${ }^{-0.034}$ & $-0 \cdot 110$ & -0.088 & 0.047 & $-0 \cdot 137$ & -0.089 & -0.045 \\
\hline Grand mean & $0 \cdot 40$ & -0.30 & -0.34 & $0 \cdot 28$ & 0.47 & $-0 \cdot 37$ & 0.03 & -0.01 \\
\hline $\begin{array}{l}\text { Socio-economic group } \\
\text { Non-manual } \\
\text { Manual } \\
\text { Unemployed } \\
\text { Other }\end{array}$ & $\begin{array}{c}\text { NS } \\
-0 \cdot 15 \\
0.02 \\
0 \cdot 12 \\
0.52\end{array}$ & $\begin{array}{r}\text { NS } \\
-0.02 \\
0.00 \\
-0 \cdot 13 \\
0.05\end{array}$ & $\begin{array}{r}* * * \\
0 \cdot 46 \\
-0 \cdot 30 \\
-0.51 \\
0.30\end{array}$ & $\begin{array}{r}* * * \\
0.24 \\
-0.19 \\
-0.34 \\
0.05\end{array}$ & $\begin{array}{c}* \\
0.17 \\
-0.19 \\
-0.11 \\
0.47\end{array}$ & $\begin{array}{l}\text { NS } \\
0 \cdot 12 \\
-0.14 \\
-0.09 \\
0.07\end{array}$ & $\begin{array}{r}\text { NS } \\
0 \cdot 12 \\
-0 \cdot 17 \\
0 \cdot 06 \\
0 \cdot 19\end{array}$ & $\begin{array}{l}\text { NS } \\
0 \cdot 13 \\
0 \cdot 00 \\
-0 \cdot 14 \\
-0.23\end{array}$ \\
\hline $\begin{array}{l}\text { Marital status } \\
\text { Married } \\
\text { Single } \\
\text { Widowed, divorced, } \\
\text { separated }\end{array}$ & $\begin{array}{c}\text { NS } \\
0.04 \\
-0.06 \\
-0.13\end{array}$ & $\begin{array}{c}\text { NS } \\
0.06 \\
-0 \cdot 16 \\
0.02\end{array}$ & $\begin{array}{l}* \\
0.14 \\
-0.16 \\
-0.61\end{array}$ & $\begin{aligned} & * \\
& 0.09 \\
&-0.05 \\
&-0.38\end{aligned}$ & $\begin{array}{l}\text { NS } \\
-0 \cdot 05 \\
0 \cdot 12 \\
-0 \cdot 15\end{array}$ & $\begin{array}{r}* \\
0 \cdot 06 \\
0 \cdot 02 \\
-0 \cdot 35\end{array}$ & \begin{tabular}{r}
\multicolumn{1}{c}{ NS } \\
$-0 \cdot 08$ \\
$0 \cdot 10$ \\
$0 \cdot 28$
\end{tabular} & $\begin{array}{c}\text { NS } \\
0.01 \\
-0.07 \\
0.06\end{array}$ \\
\hline $\begin{array}{l}\text { Religion } \\
\text { Protestant } \\
\text { Catholic } \\
\text { Other }\end{array}$ & $\begin{array}{r}* * \\
-0 \cdot 17 \\
0 \cdot 24 \\
-0 \cdot 16\end{array}$ & $\begin{array}{c}\text { NS } \\
-0.05 \\
0.05 \\
0.13\end{array}$ & $\begin{array}{c}\text { NS } \\
0 \cdot 00 \\
-0 \cdot 02 \\
0 \cdot 18\end{array}$ & $\begin{array}{l}\text { NS } \\
-0.01 \\
-0.02 \\
0.53\end{array}$ & $\begin{array}{c}\text { NS } \\
0 \cdot 01 \\
-0 \cdot 01 \\
0 \cdot 00\end{array}$ & $\begin{array}{c}\text { NS } \\
0 \cdot 00 \\
-0 \cdot 02 \\
0 \cdot 31\end{array}$ & $\begin{array}{c}\text { NS } \\
-0 \cdot 12 \\
0 \cdot 15 \\
0 \cdot 08\end{array}$ & $\begin{array}{c}\text { NS } \\
-0.06 \\
0.09 \\
-0 \cdot 10\end{array}$ \\
\hline $\begin{array}{l}\text { Geographical location } \\
\text { Urban } \\
\text { Rural }\end{array}$ & $\begin{array}{r}* \\
-0.32 \\
0.08\end{array}$ & $\begin{array}{l}\text { NS } \\
-0.07 \\
0.02\end{array}$ & $\begin{array}{c}\text { NS } \\
0.05 \\
-0.01\end{array}$ & $\begin{array}{l}\text { NS } \\
0.04 \\
-0.01\end{array}$ & $\begin{array}{c}\text { NS } \\
0 \cdot 17 \\
-0 \cdot 04\end{array}$ & $\begin{array}{l}\text { NS } \\
0.15 \\
-0.05\end{array}$ & $\begin{array}{l}\text { NS } \\
-0.02 \\
0.01\end{array}$ & $\begin{array}{l}\text { NS } \\
-0.20 \\
0.06\end{array}$ \\
\hline $\begin{array}{l}\text { Smoking } \\
\text { Current } \\
\text { Ex-smoker } \\
\text { Never smoke }\end{array}$ & $\begin{array}{l}\text { NS } \\
-0.12 \\
-0.13 \\
0.18\end{array}$ & $\begin{array}{l}\text { NS } \\
-0 \cdot 11 \\
-0 \cdot 01 \\
0 \cdot 10\end{array}$ & $\begin{array}{c}\text { NS } \\
-0 \cdot 11 \\
0 \cdot 14 \\
0 \cdot 06\end{array}$ & $\begin{array}{r}* * \\
-0 \cdot 17 \\
-0 \cdot 04 \\
0 \cdot 16\end{array}$ & $\begin{array}{c}\text { NS } \\
0 \cdot 02 \\
0 \cdot 07 \\
-0.05\end{array}$ & $\begin{array}{c}\text { NS } \\
-0.06 \\
-0.03 \\
0.06\end{array}$ & $\begin{array}{c}\text { NS } \\
0.00 \\
-0.01 \\
0.00\end{array}$ & $\begin{array}{c}\text { NS } \\
-0.04 \\
-0.09 \\
-0.01\end{array}$ \\
\hline $\begin{array}{l}\text { Drinking } \\
\text { > Once weekly } \\
\text { Once weekly } \\
\text { < Once weekly } \\
\text { Never }\end{array}$ & $\begin{array}{r}* * \\
-0.13 \\
-0.25 \\
0.29 \\
0.29\end{array}$ & $\begin{array}{r}{ }^{* *} \\
-0 \cdot 15 \\
-0 \cdot 20 \\
0 \cdot 02 \\
0 \cdot 20\end{array}$ & $\begin{array}{l}\text { NS } \\
-0 \cdot 12 \\
-0 \cdot 03 \\
0 \cdot 02 \\
0 \cdot 15\end{array}$ & $\begin{array}{r}* \\
0.00 \\
0.29 \\
-0.04 \\
-0 \cdot 15\end{array}$ & $\begin{array}{r}* \\
-0 \cdot 14 \\
0 \cdot 29 \\
-0 \cdot 13 \\
-0 \cdot 21\end{array}$ & $\begin{array}{r}* * * \\
0.08 \\
0 \cdot 39 \\
-0.08 \\
-0.21\end{array}$ & $\begin{array}{r}* * * \\
0 \cdot 18 \\
0.31 \\
-0.29 \\
-0.43\end{array}$ & $\begin{array}{r}\text { NS } \\
0.22 \\
-0.06 \\
0.01 \\
-0 \cdot 12\end{array}$ \\
\hline $\begin{array}{l}\text { No. in household } \\
\quad 1 \\
2 \\
3 \\
>3\end{array}$ & $\begin{array}{c}\text { NS } \\
-0.29 \\
0.05 \\
0.00 \\
0.05\end{array}$ & $\begin{array}{r}\text { NS } \\
0.20 \\
-0.01 \\
0.00 \\
-0.03\end{array}$ & $\begin{array}{l}\text { NS } \\
0 \cdot 44 \\
0 \cdot 10 \\
-0 \cdot 13 \\
-0 \cdot 09\end{array}$ & $\begin{array}{r}\text { NS } \\
0 \cdot 32 \\
-0.01 \\
0.09 \\
-0.07\end{array}$ & $\begin{array}{l}\text { NS } \\
0.01 \\
0.16 \\
0.01 \\
-0.06\end{array}$ & $\begin{array}{l}\text { NS } \\
0.16 \\
0.08 \\
0.05 \\
-0.08\end{array}$ & $\begin{array}{c}\text { NS } \\
-0.51 \\
0.02 \\
0.19 \\
0.05\end{array}$ & $\begin{array}{r}\text { NS } \\
0 \cdot 18 \\
-0.02 \\
0.04 \\
-0.03\end{array}$ \\
\hline
\end{tabular}

BMI, body mass index (weight $/$ height $^{2}$ ); NS, not significant.

$* P<0.05, * * P<0.01, * * * P<0.001$.

† For details, see pp. 322-324.

the association was positive for men from non-manual households and from other (unclassified) households. Marital status had a significant $(P<0.05)$ effect in the female cohort; women who were widowed, separated or divorced tended to avoid this dietary behaviour. There were no significant associations between household size, religious group, geographical location or smoking habit and this eating pattern. However, drinking habit was significantly $(P<0.05$ for men and $P<0.001$ for women) associated with adherence 
to this pattern of eating; men and women who drank once weekly favoured component three.

\section{Component four}

There were few significant associations between this component ('meat and two veg' diet) and sociodemographic and lifestyle factors. The only significant $(P<0.001)$ association was seen for drinking habit in the male sample; men drinking once weekly or more often were more likely to adhere to this regimen.

\section{DISCUSSION}

Dietary practices vary between and within populations. Food consumption and nutrient intakes are known to vary with sex, age, smoking habit and, to some extent, occupational class in Great Britain (Bingham et al. 1981; Fehily et al. 1984 b; Barasi et al. 1985) and Northern Ireland (Barker et al. 1989). The relationships between these sociocultural demographics and nutrient intake are similar in Northern Ireland to other parts of the UK, as are absolute nutrient intakes (Barker et al. 1989). The present investigation of eating patterns has shown that various population groups in Northern Ireland have distinct dietary behaviours in terms of food predominance and association.

The first dietary pattern, accounting for $6.7 \%$ of the total variation, was the most identifiable dietary behaviour to emerge from the analysis. Consumption of staple indigenous foods such as bread and potatoes was an important element in this behaviour, as was the consumption of fat- and carbohydrate-rich foods such as cakes, puddings, buns and pastries. The concomitant relationships between sociocultural demographics and this traditional diet are especially interesting; older, rural, Roman Catholic male subjects tended to this pattern and although women were less likely to follow this pattern, those who did so tended to be older. Due to the strong age effect it is clear that this regimen has historical roots. The predominance of fat- and carbohydrate-rich foods such as puddings and cakes within this dietary behaviour may be seen to be a legacy of the late 1950s and early 1960s when home baking was in its heyday. Indeed, a fall in the consumption of cakes and pastries during the 1960 s ( $9 \%$ decrease) and 1970s (38\% decrease) was observed by King (1983) in an analysis of trends in meal planning and eating habits in Great Britain using statistics from the National Food Survey. However, it would seem that an identifiable population group in Northern Ireland has retained a traditional pattern of eating, reflecting a trend of stability and conservatism in food choice in Northern Ireland.

The associations between the traditional diet and drinking habits are also worthy of comment. Alcohol consumption profiles in Northern Ireland are quite different from other parts of the UK. Studies (Blaney \& MacKenzie, 1978; Policy Planning Research Unit, 1982) have shown that the proportion of total abstainers is much greater in Northern Ireland, although abstinence from alcohol has fallen in the last decade (Barker et al. 1989). Followers of the traditional diet tended to be non-drinkers and were more likely to live in rural areas, confirming the traditional nature of this eating behaviour.

The second dietary pattern identified was a more diverse and varied diet containing foods such as pasta and rice, patés, cooked meat and egg and cheese dishes, which are less vernacular and more international in origin. Other foods ranking high in this behaviour were fruit and vegetables, perhaps reflecting increased health awareness in food choice.

A strong sex effect was observed, with women tending to this pattern. The fact that women preferred this diverse diet supports the finding that women are less averse to dietary change than men (Charles \& Kerr, 1988). Through their role as food providers they will be more aware of contemporary food advertising, leisure-reading material featuring articles on experimental and inventive cooking, and educational material on the relationships 
between food, nutrition and health. The finding that non-smokers tended to this diet also supports the hypothesis that this dietary pattern may be partially motivated by health interests.

This varied, cosmopolitan diet was preferred by men and women from the non-manual classes, who in terms of income can afford a more diverse diet (McKenzie, 1974; Charles \& Kerr, 1988) and to whom food selection has strong social and health connotations (Charles \& Kerr, 1988). The Swiss study of Gex-Fabry et al. (1988) also demonstrated a social hierarchy in dietary behaviour; senior executives, professionals and general managers tended to eat greater amounts of fish, vegetables and fruit while manual workers tended to eat inexpensive and satiating foods such as potatoes, pasta, bread and pork meat.

The presence of a spouse was also associated with this pattern of eating. Married men and women were more likely to be adherents of the cosmopolitan diet. Again this observation reflects the importance of women as food providers within the family, with the gravitation towards a varied, diverse, cosmopolitan diet appearing to stem from women's role as wives. An effect of household size was also observed, with larger households tending to avoid this eating pattern. It would appear, therefore, that the presence of children has influences on eating behaviour. The foods that comprise this diet are adult foods such as pasta, rice, cooked meat dishes, patés, fatty fish and shellfish whilst foods that may be classified as children's foods such as baked beans, sausages and chips were avoided. In their study of women, food and families, Charles \& Kerr (1988) noted that foods were ranked in a hierarchy and have different social values, with children's foods (for example, baked beans, crisps, fish fingers, biscuits) having low status.

The third dietary pattern identified was based on convenience food. Beer, chips, soft drinks, canned peas and beans, sausages, cheese and yoghurt had high positive loadings. These foods, low in terms of culinary complexity, were favoured by younger subjects and there was a strong sex effect with men most likely to adhere to a diet of fast and convenience foods. Drinking habits also influenced this dietary behaviour; men and women who drank at least once weekly gravitated towards a convenience diet. This dietary behaviour was also associated with relative BMI in the female cohort; women consuming these foods were more likely to be below the desirable weight range. This effect is consistent with the finding of Gex-Fabry et al. (1988) that subjects below the desirable weight range seem to consume more 'filling' foods, such as sausages, cheese, pasta and potatoes.

The consumption of convenience foods may be seen as a relatively recent dietary trend, since foods such as chips, hamburgers, fried fish and soft drinks have become increasingly available through the proliferation of fast-food outlets. King (1983) noted the growing proportion of adults buying take-away food in Great Britain between 1974 (33\%) and 1981 $(57 \%)$. It would, therefore, appear that the consumption of take-away and convenience foods (for example, cheese, yoghurt, nuts and confectionery) has become established as a dietary practice in Northern Ireland. Indeed, in a social history of diet in England and Wales from 1945 to the mid-1970s, Burnett (1979) states 'But what is now an outstanding and apparently irreversible trend in English diet in recent years is the growth in demand for "convenience foods", This effect may be due to increasing urbanization, increases in real income, and lifestyles which allow little time for shopping, preparation and cooking of foods. The fact that men consume more of these foods confirms the reluctance of men to participate in domestic duties involving food preparation and provision (Charles \& Kerr, 1988).

The final dietary pattern identified was a 'meat and two veg' diet. This dietary behaviour generally transcended sociocultural divisions. However it was favoured by men who drank once weekly or more, particularly those from non-manual and other (unclassified) households. It should be noted that the latter group are heterogeneous in terms of 
occupational class and many were so classified because the head of the household was a woman who had never worked, and hence did not fall into any occupational group.

Charles \& Kerr (1988) found that 'meat and two veg' was the predominant food culture in Great Britain, with subjects from all classes espousing and aspiring to this eating pattern. They noted, however, that while women from low-income households would have liked to provide high status meat (for example, roasts, steak, chops and fowl) on a regular or even daily basis, this was not possible due to economic constraints and these foods were, thus, reserved for Sunday lunch or special occasions. The relationships between the 'meat and two veg' diet and socio-economic group found in the present study bear out these observations. In addition, Charles \& Kerr (1988) concluded that meat and alcohol were foods of high social status within the dominant food ideology and their consumption was strongly associated with maleness. The positive associations observed in the present study between the 'meat and two veg' diet, males and alcohol consumption support these findings.

In conclusion, it appears that eating patterns are governed by a number of inter-related sociodemographics, which interact with the lifestyle behaviours of smoking and drinking habit. However, anthropometric variables appear to have less influence on dietary behaviour. The different dietary behaviours of, for example, men and women, old and young, manual and non-manual occupational groups reinforce the fact that food meets needs that are both biologically and socially constructed. The identification of four distinct eating patterns in Northern Ireland and the elucidation of their sociocultural determinants must be important prerequisites in any intervention campaign designed to change the population's eating habits and to improve its health.

The authors wish to acknowledge the Health Promotion Research Trust for financial support of this study.

\section{REFERENCES}

Barasi, M. E., Phillips, K. M. \& Burr, M. L. (1985). A weighed dietary survey of women in South Wales. Human Nutrition: Applied Nutrition 39A, $189-194$.

Barker, M. E., McClean, S. I., McKenna, P. G., Reid, N. G., Strain, J. J., Thompson, K. A., Williamson, A. P. \& Wright, M. E. (1989). Diet, Lifestyle and Health in Northern Ireland. A Report to the Health Promotion Research Trust. Coleraine: University of Ulster.

Bingham, S. A., McNeil, N. 1. \& Cummings, J. H. (1981). The diet of individuals: a study of a randomly-chosen cross section of British adults in a Cambridgeshire village. British Journal of Nutrition 45, 189-194.

Blaney, R. \& MacKenzie, G. (1978). A Northern Ireland Community Health Study: Report to the Department of Health and Social Services. Belfast: Department of Community Medicine, Queen's University of Belfast.

Burnett, J. (1979). Plenty and Want. A Social History of Diet in England and Wales from 1815 to the Present Day. London: Scholar Press.

Cade, J. E. \& Margetts, B. M. (1988). Nutrient sources in the English diet: quantitative data from three English towns. International Joumal of Epidemiology 17, 844-848.

Charles, N. \& Kerr, M. (1988). Women, Food and Families. Manchester and New York: Manchester University Press.

Ellis, J. A., Wiens, J. A., Rodell, C. F. \& Anway, J. C. (1976). A conceptual model of diet selection as an ecosystem process. Joumal of Theoretical Biology 60, 93-108.

Fehily, A. (1983). Epidemiology for nutritionists: 4, survey methods. Human Nutrition: Applied Nutrition 38A, 270-276.

Fehily, A., Phillips, K. M. \& Sweetnam, P. M. (1984a). A weighed dietary survey of men in Caerphilly, South Wales. Human Nutrition: Applied Nutrition 38A, $270-276$.

Fehily, A. M., Phillips, K. M. \& Yarnell, J. W. G. (1984b). Diet, smoking, social class and body mass index in the Caerphilly Heart Disease Study. American Journal of Clinical Nutrition 40, 827-833.

Gex-Fabry, M., Raymond, L. \& Jeanneret, O. (1988). Multivariate analysis of dietary patterns in 939 Swiss adults. Sociodemographic parameters and alcohol consumption profiles. International Journal of Epidemiology 17, 548-555.

Hackett, A. F., Rugg-Gunn, A. J., Appleton, D. R. \& Coombs, A. (1986). Dietary sources of energy, protein, fat and fibre in 375 English adolescents. Human Nutrition: Applied Nutrition 40A, 176-184. 
Hara, N., Sakata, K., Masaki, N., Nagai, M., Fujita, Y., Hashimoto, T. \& Yanagawa, H. (1985). Statistical analyses of food consumption and digestive-tract cancers in Japan. Nutrition and Cancer 6, 220-228.

Hirayama, T. (1985). Mortality in Japanese with life-styles similar to Seventh-Day Adventists: strategy for risk reduction by life-style modification. National Cancer Institute Monograph no. 69, pp. 143-153. Bethesda Maryland: published jointly by US Department of Health and Human Services, Public Health Service, National Institute of Health and the National Cancer Institute.

Jellife, D. B. (1967). Parallel food classifications in developing and industrialized countries. American Journal of Clinical Nutrition 20, 279-281.

King, S. (1983). Trends in meal planning and eating habits. In Food and People, pp. 43-65 [M. B. Turner, editor]. London: John Libbey and Co.

Kish, L. (1965). Survey Sampling. New York: Wiley.

McKenzie, J. (1974). The impact of economic and social status on food choice. Proceedings of the Nutrition Society 33, 67-73.

Marr, J. W. (1971). Individual dietary surveys: purposes and methods. World Review of Nutrition and Dietetics 13, $105-164$.

Office of Population, Censuses and Surveys (1980). Classification of Occupations. London: H.M. Stationery Office.

Passim, H. \& Bennet, J. W. (1943). Social process and dietary change. In The Problem of Changing Food Habits. Bulletin no. 108, p. 113. Washington, DC: National Academy of Sciences.

Policy Planning and Research Unit (1982). Drinking Practices in Northern Ireland: a Survey Carried Out on Behalf of The Department of Health and Social Services $(N I)$ [J. Harbinson and J. Haire, editors]. Belfast: Department of Finance and Personnel.

Schwerin, H. A., Stanton, J. L., Riley, A. M., Schaefer, A. E., Leveille, G. A., Elliott, J. G., Warwick, K. M. \& Brett, B. E. (1981). Food eating patterns and health: a re-examination of the Ten-State and HANES 1 surveys. American Journal of Clinical Nutrition 34, 568-580.

Scherwin, H. S., Stanton, J. L., Smith, J. L., Riley, A. M. \& Brett, B. E. (1982). Food, eating habits and health: a further examination of the relationship between food eating patterns and nutritional health. American Journal of Clinical Nutrition 35, 1319-1325.

SPSSX (1983). SPSSX User's Guide. New York: McGraw-Hill.

Thomson, M., Fulton, M., Wood, D. A., Brown, S., Elton, R. A., Birtwhistle, A. \& Oliver, M. F. (1985). A comparison of the nutrient intake of some Scotsmen with dietary recommendations. Human Nutrition: Applied Nutrition 39A, 443-455. 